
\title{
Tras las huellas de la forma urbana en la Isla Grande de Tierra del Fuego,
} Argentina - Chile.

\author{
Lara Espindola Gerhardt \\ Departamento de Urbanismo y Ordenación del Territorio (DUOT) UPC \\ Directores: Joaquim Sabaté Bel, Carles Llop Torne \\ laraespindola@gmail.com
}

\section{RESUMEN}

Las reglas de la forma urbana de la Isla Grande de Tierra del Fuego se han visto condicionadas principalmente por las huellas de su territorio, su paisaje, sus primeros habitantes y por sus colonizadores.

En este contexto, las ciudades actuales de dicha isla tienen una apariencia figurativa compatible a los patrones del modelo clásico español, con un sistema de parcelación y una tipología arquitectónica repetida, con la cuadricula y la manzana regular cuadrada asegurando la racionalidad de la organización, como la característica de la urbanización no solo de esta isla sino de todo un continente.

Este artículo propuso analizar la incidencia del palimpsesto ${ }^{1}$ de Karukinka ${ }^{2}$, es decir, ir tras las huellas de la forma urbana en el territorio y el paisaje, y su posible vinculación con los pueblos originarios, los Selk'nam. Y a su vez analizar la continuidad de la retícula colonizadora en el territorio de Karukinka o Isla Grande de Tierra del Fuego.

Palabras Clave: Paisaje austral, Territorio, Palimpsesto, Reglas forma urbana, Ordenanzas

\section{ABSTRACT}

Mainly the rules of the urban form of the Isla Grande de Tierra del Fuego have been conditioned by the traces of its territory, its landscape, its first inhabitants and by its colonizers.

In this context, the current cities of that island have a figurative appearance compatible to the patterns of the classic Spanish model, with a system of subdivision and a repeated architectural typology, with the grid, the square regular block assuring the rationality of the organization as the characteristic of the urbanization not only of this island but of a whole continent.

This article proposed to analyze the incidence of the palimpsest ${ }^{1}$ of Karukinka ${ }^{2}$, that is, to follow the traces of the urban form in the territory and landscape, and its possible link with the native peoples, the Selk'nam. And in turn analyze continuity of the colonizing grid in the territory of Karukinka or Isla Grande de Tierra del Fuego.

Key words: Southern landscape, Territory, Palimpsest, Rules of urban form, Ordinances

\footnotetext{
1 Palimpsesto: literalmente es un manuscrito antiguo que conserva las huellas de una escritura anterior, borrada artificialmente. También es utilizado el significado de palimpsesto como una metáfora que simboliza que la ciudad es un pergamino en el cual se reescribe una historia. Es decir, un depósito de historias representadas por capas a la que se le añadirán otras capas sucesivamente (Corboz, 1983).

2 Karukinka: es el nombre que le dieron los originarios Selk'nam a su territorio: la Isla Grande de Tierra del Fuego (actualmente Argentina - Chile) y significa "nuestra tierra".
} 


\section{INTRODUCCIÓN}

\section{"... le debemos a las Ordenanzas buena parte de la belleza de las ciudades..." Joaquim Sabaté Bel}

Manuel de Solà-Morales (1981 y 1999) plantea dos cuestiones, la primera es la necesidad de interpretar al territorio como una construcción histórica como un producto artificial de la intervención humana. Y la segunda es que la forma de las ciudades se construye siempre desde el paisaje y desde la arquitectura. Aunque también admite que existen otras ciudades en las que se ha querido vincular los datos de la arquitectura de manera consciente y voluntaria, convirtiendo su relación en una creación formal en sí misma. Así es como el urbanismo introduce en estas ciudades sus formas propias, a través de los instrumentos administrativos de la planificación urbana. Son esos atributos los que podrían hacer de la creación de las formas urbanas, un hecho de cultura y una obra de arte, la "cultura de las ciudades" a la que ya se refería (Mumford 1957): hacer de la fábrica urbana un proyecto consciente, una obra humana.

Según Joaquim Sabaté Bel (1999) las reglas urbanas son instrucciones técnicas u ordenanzas o reglamentos urbanos de la arquitectura. Un buen ejemplo de cómo controlar el orden formal de las operaciones de construcción y remodelación de la ciudad, que han devenido en la base en que descansa su singular valor urbanístico. Además, resalta que la belleza de muchas ciudades, debido a su regularidad y repetición de cosas en común, tiene una enorme deuda para con la ordenanza. Entendida la Ordenanza como instrumento fundamental para la ordenación y control de la ciudad, como condición vinculante de la forma de las edificaciones, como idea de ciudad y de la forma de la ciudad que se quiere.

Como afirma Terán (1997) la ciudad hispanoamericana nació, se configuró y se desarrolló con una notable homogeneidad y coherencia formal, a través de un sistema de parcelación y una tipología arquitectónica repetida. La permanencia de la cuadricula y su adaptación como forma mayoritaria de soporte para las extensiones asegura la racionalidad de la organización básica, característica de la urbanización de todo un continente.

Este artículo pretende poner en evidencia las huellas de la forma urbana en el territorio y su posible vinculación con los pueblos originarios, los Selk'nam. Y a su vez analizar continuidad de la retícula colonizadora en el territorio de Karukinka o Isla Grande de Tierra del Fuego.

\section{LA FORMA BIO-FISICA ${ }^{3}$ DE KARUKINKA}

\section{“... Creemos ser país y la verdad es que somos apenas paisaje..." Nicanor Parra}

Como afirma de Solà-Morales (1999) el agua, el fuego, el aire y la tierra, han sido las cuestiones sobre las que la historia de la construcción urbana ha elaborado sucesivos códigos de buen comportamiento, con el fin de hacer la fábrica de las ciudades más cómoda, equitativa y bella. Para llegar a la forma urbana es necesario vislumbrar las huellas del proceso de construcción y elaboración. En este caso partiendo de la forma bio-física de Karukinka, que significa "nuestra tierra", nombre dado por los aborígenes Selk'nam a la después denominada Isla Grande de Tierra del Fuego

Karukinka es una isla que se encuentra al sur del paralelo 52, en el extremo (más extremo) sur de América, separada por el estrecho de Magallanes. Forma parte del archipiélago fueguino y su superficie es de $47.992 \mathrm{~km}^{2}$. Limita con el canal de Beagle al sur, el océano Atlántico al este y el océano Pacifico al oeste (ver Fig. 01). Es un territorio intenso, remoto, complejo con un clima muy riguroso. Entre sus elementos geográficos, disimiles y contrapuestos, conviven lagos y cordilleras, praderas y glaciares. Llama la atención el contorno de sus costas, las bahías, los fiordos, las praderas ventosas, las tierras bajas, las turberas, los grandes cuerpos de agua y los bosques de lenga.

\footnotetext{
${ }^{3}$ Bio - Física: del latín Bio = ßı y Fisica = phyšca. Autodefinición referida a la forma tanto física como biológica de un territorio. 

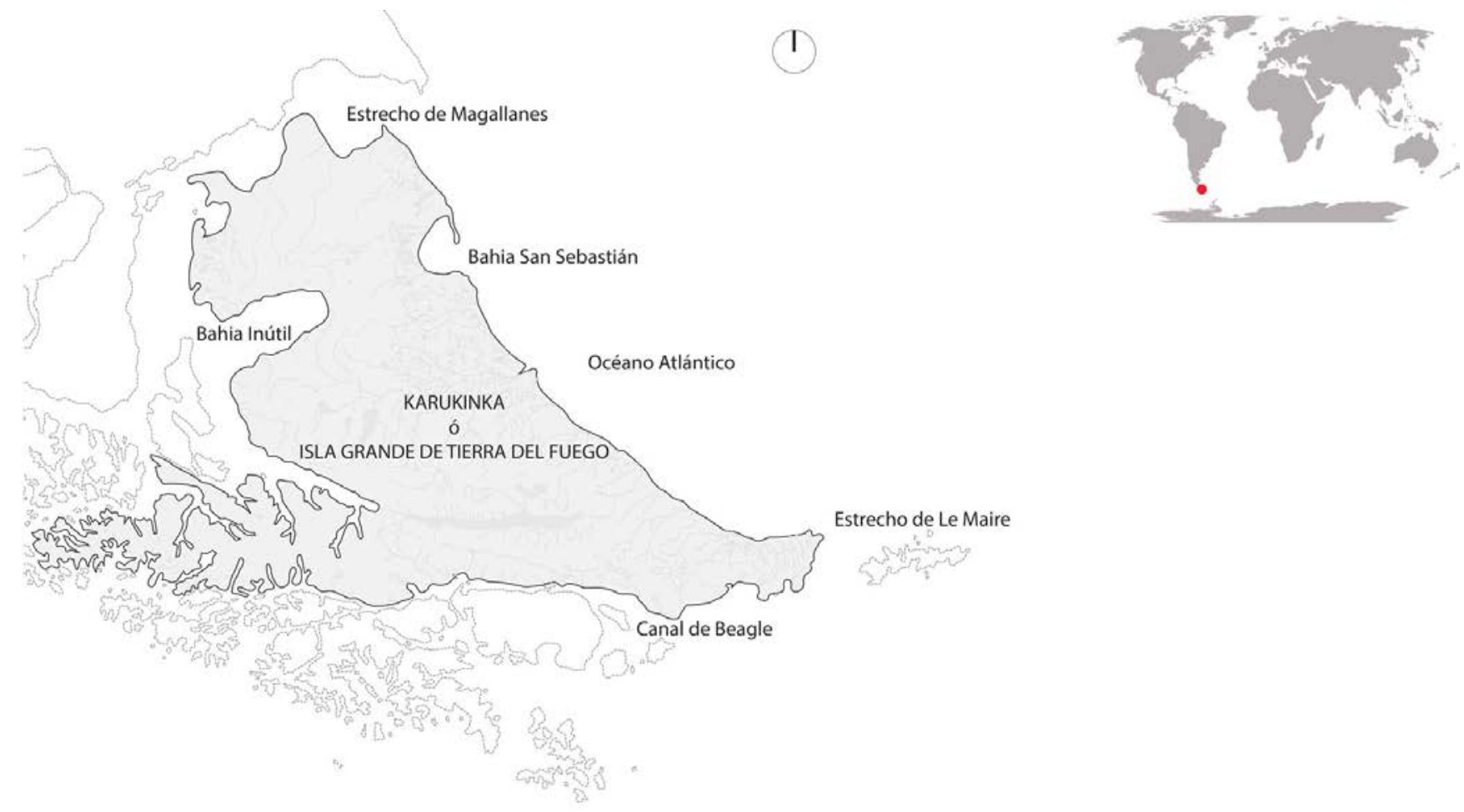

Fig. 01. Ubicación de Karukinka o Isla Grande de Tierra del Fuego. Fuente: Elaboración propia, a partir de Google Maps Pro 2018.

Surge como resultado de un proceso de evolución geológica, que demoró decenas o centenas de milenios y tuvo su culminación en la última de las grandes glaciaciones patagónicas. El progresivo retiro de los hielos labró los futuros canales que la separarían de la Patagonia y del resto del archipiélago occidental, acompañado de hundimientos y solevantamientos, fue dando forma física a la gran tierra del sur, que acabaría por ser una isla al cortarse el puente terrestre que la unía con su vecino territorio boreal.

Según su morfología, la isla se divide en dos sectores muy diferenciados. Hacia el norte, por mesetas y llanuras onduladas. Y al sur, por la terminación austral de la Cordillera de los Andes. El punto más alto se encuentra en la Cordillera de Darwin. Hacia el fondo hay lagos y lagunas de origen glaciar como el Lago Fagnano. Las condiciones climáticas particulares favorecen el desarrollo de turbales.

Tras las huellas de las reglas de la forma urbana en Karukinka me encuentro con la memoria territorial, con todo aquello que le dio la forma física a la isla. Entre ellos se destaca la composición geológica (ver Fig. 02), la criósfera, la hidrografía (ver Fig. 03), el modelo de elevación, la vegetación (ver Fig. 04) y el mapa astral. Estas situaciones de memoria territorial produjeron patrones de vida en la isla, como las formas de ocupación del pasado y del presente. 

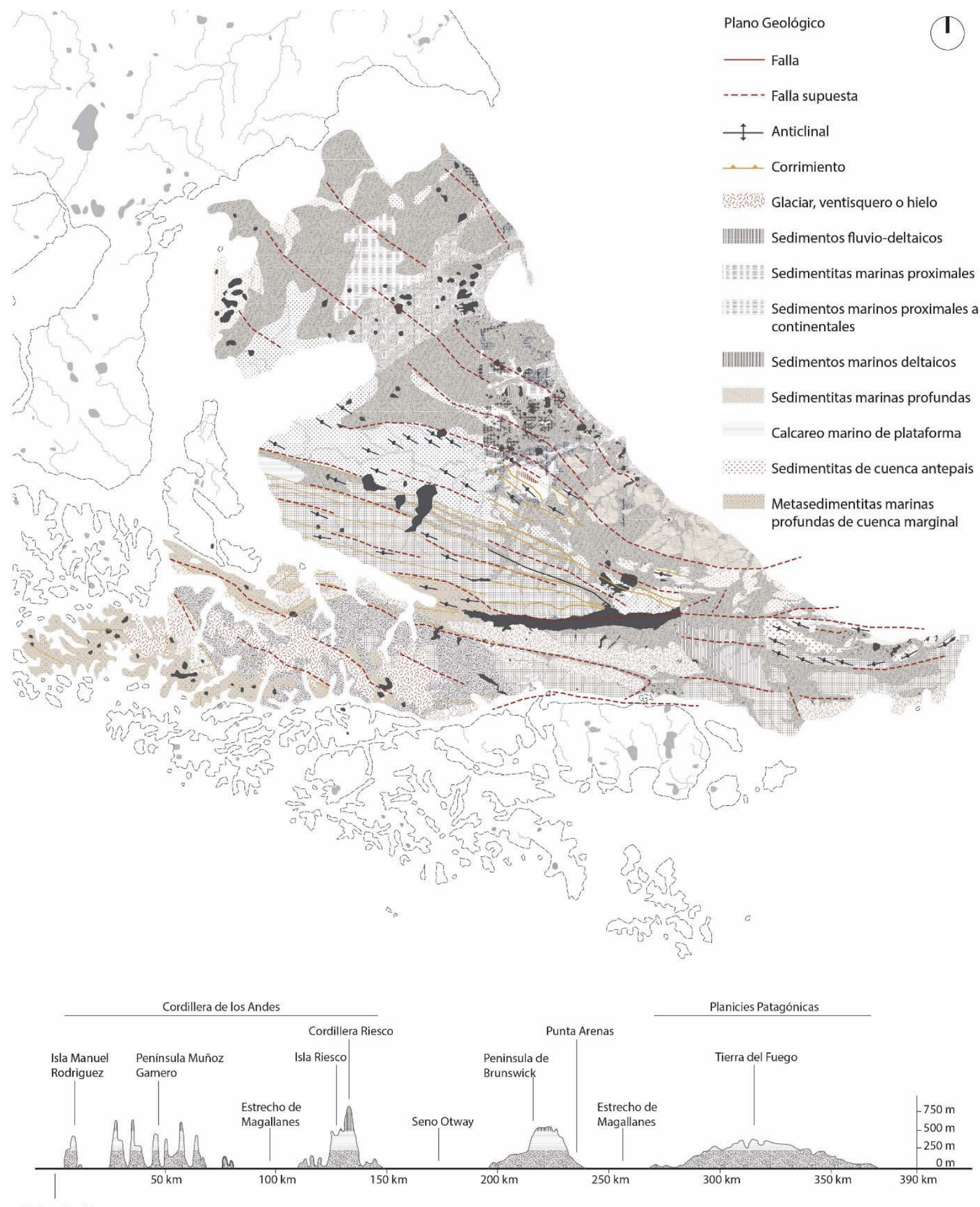

Océano Pacifico

Fig. 02. Arriba: Plano Geológico de Isla Grande de Tierra del Fuego. Fuente: Elaboración propia, a partir de la unión los mapas del Servicio Geológico Minero Argentino e Instituto Geográfico Militar Chileno. Abajo: Perfil topográfico interpretativo, latitud sur entre los 52ㅇ y 53으, zona Austral. Fuente: Elaboración propia a partir de la reinterpretación del grafico del Instituto Geográfico Militar Argentino (IGM, 2012). 


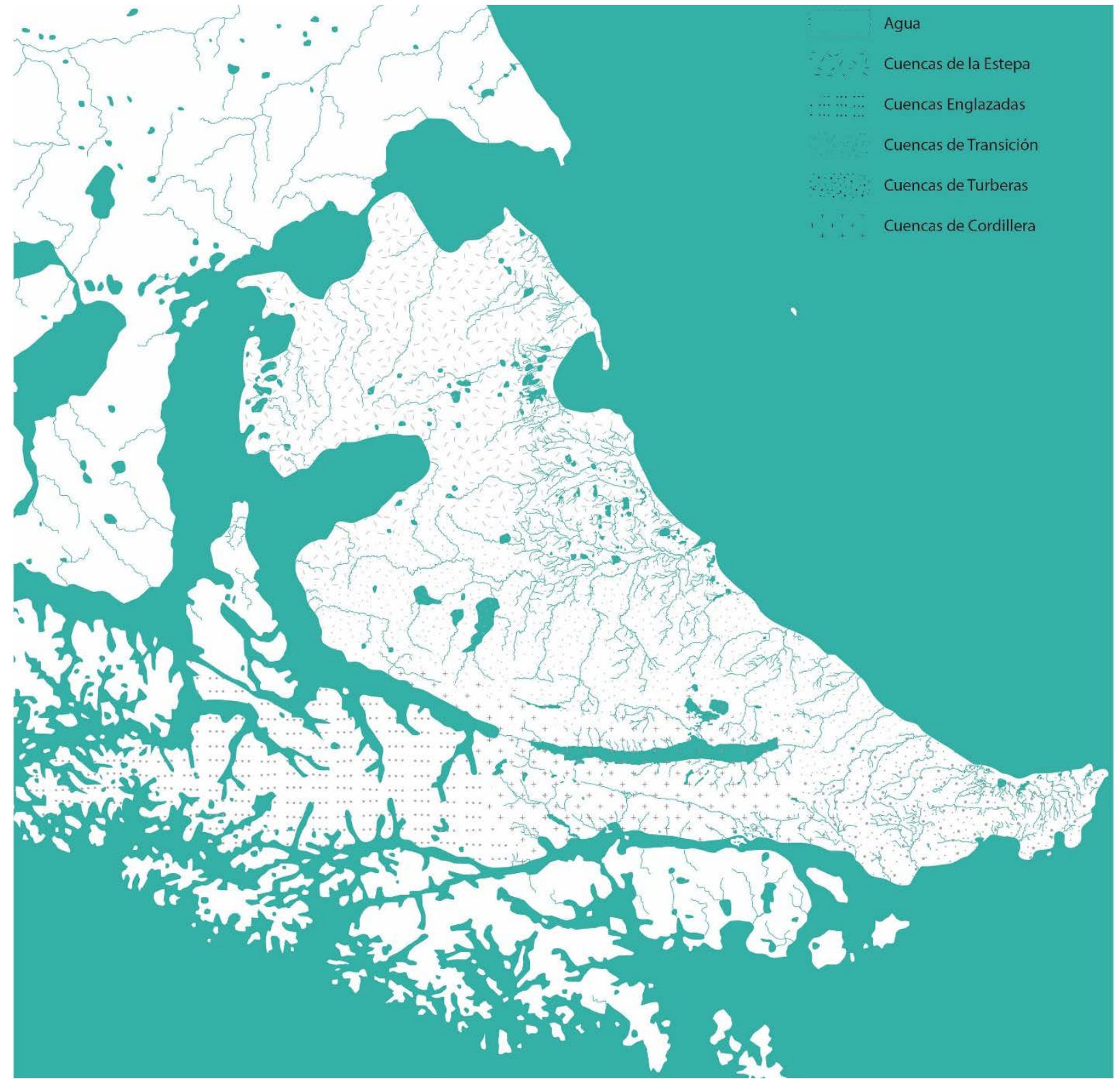

Fig. 03. Plano Hidrológico y Cuencas de la Isla Grande de Tierra del Fuego. Fuente: Elaboración propia, a partir de información del Instituto Geográfico Militar Argentino y el Instituto Geográfico Militar Chileno. 


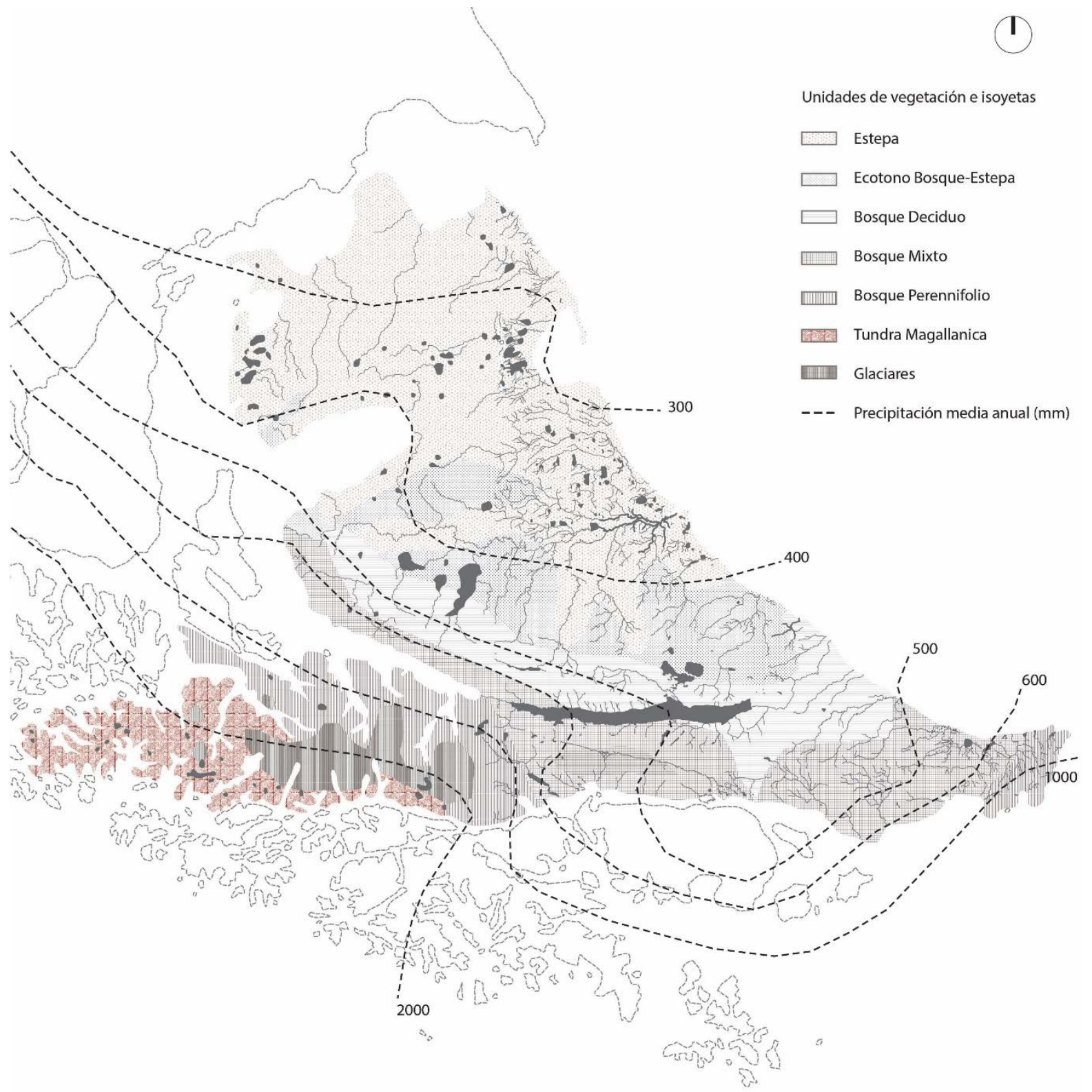

Fig. 04. Plano de unidades de vegetación e isoyetas. Fuente: Elaboración propia, a partir de publicación realizada por Gajardo (1993).

El mapa celeste astral en la isla ha sido muy útil para los pueblos originarios, los navegantes y los colonizadores, no solo para guiarse en sus viajes sino también como punto de partida para constituir la forma del territorio. Se perciben las constelaciones y estrellas como Orión, Sirio, Proción y la Cruz del Sur (ver Fig. 05). Además, debido a su ubicación austral extrema, son muy importantes los solsticios y los equinoccios, por ejemplo, en el solsticio de invierno del 21 de junio, la noche es la más larga del año y la luz diurna solo dura seis horas. 

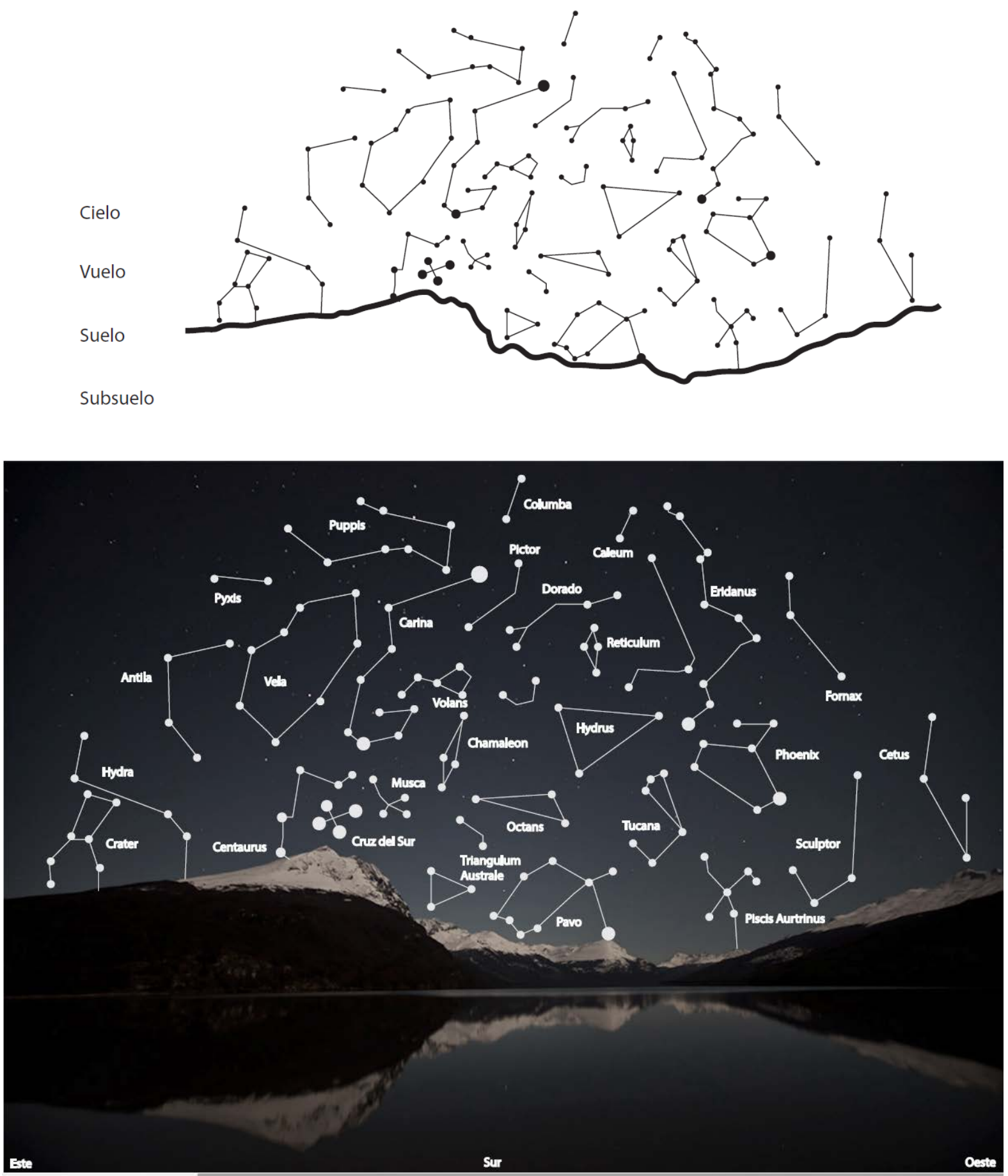

Fig. 05. El gran rio de los espíritus buenos ${ }^{4}$. Cielo Nocturno, Isla Grande de Tierra del Fuego. Arriba: Idea conceptual propia sobre los distintos estratos territoriales. Fuente: Elaboración propia. Abajo: Mirando hacia el sur el cielo nocturno en Lago Acigami, Isla Grande de Tierra del Fuego, durante las breves noches estivales de febrero 2016. Fuente: Elaboración propia, a partir de superposición de la fotografía tomada por Víctor Bibe y la carta celeste del mes de febrero en el hemisferio sur, orientación sur (González Mármol, 2012).

${ }^{4}$ El gran rio de los espíritus buenos: significado Selk’nam de la Vía Láctea 


\section{LA FORMA ANTROPICA ${ }^{5}$ NOMADE DE KARUKINKA}

"... el inicio de la simbiosis (juntos - vivir) de la matriz bio - física y la matriz antropológica de Karukinka, se produjo en una de las ultimas glaciaciones patagónicas..."

\subsection{Acceso a Karukinka}

Debido a su actual concepción geográfica insular merece la pena cuestionar como ha sido desde sus orígenes el acceso a Karukinka. Lo interesante de esta pregunta quizás esté en lo maravilloso del inicio de la simbiosis de un hecho geomorfológico y uno antropológico, al que denomino "hecho geo-umbilical" (ver Fig.06). Hace 24.000 años se produjo el cordón umbilical geográfico que permitió el ingreso tanto de corrientes de población humana, como de flora y fauna. Esta región entre la Patagonia y la Isla Grande de Tierra del Fuego se conformó por un istmo en la primera angostura del Estrecho de Magallanes y luego cuando se rompió éste, por un segundo istmo en la segunda angostura. Este proceso fue desde 16.500 años hasta 8.700 años antes del presente.

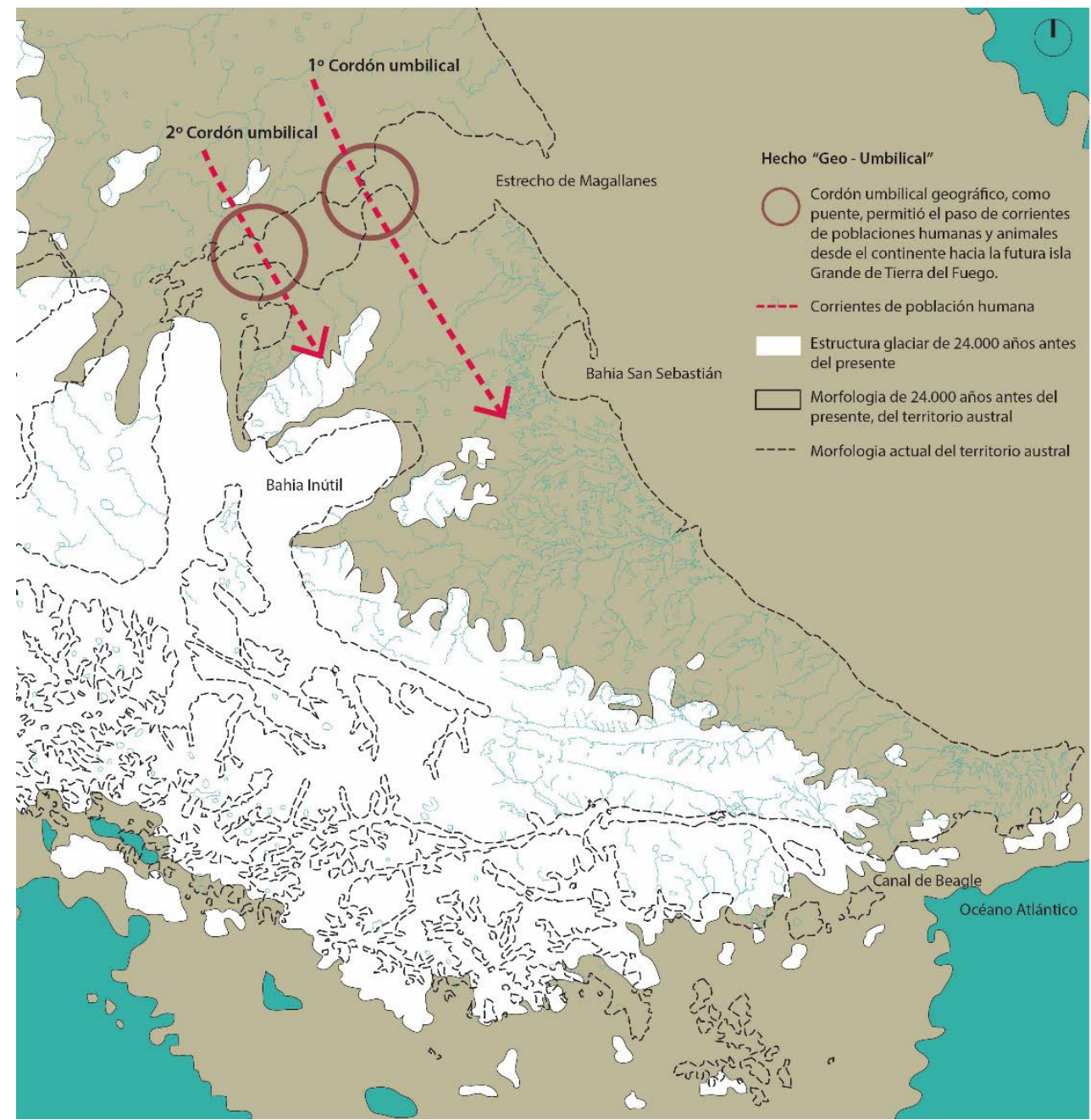

Fig. 06. Comparación de la situación física actual de la Isla Grande de Tierra del Fuego, con la extensión del manto de hielo y lóbulos de descarga durante el Último Máximo Glaciar (UMG, aprox. 24 ka A.P.; Rabassa, 2008), con un hipotético nivel del mar 140m por debajo del actual. Fuente: Elaboración propia, a partir del artículo científico escrito por Ponce y Rabassa, 2012.

\footnotetext{
${ }^{5}$ Antrópica: es lo originado por la actividad humana.
} 
Los grupos originarios que cruzaron el estrecho de Magallanes durante la última era glaciar tenían diferentes modos de vida, los que habitaban tierra adentro y los que se adaptaron a la vida litoral marítima. Pero ambos compartían el hecho de que eran nómades dentro de la misma isla. Según M. Gusinde (1980), los primeros vivían de la caza (cazadores pedestres) y se alimentaban de guanacos y aves. Y los segundos eran canoeros y se alimentaban de la pesca y de mamíferos marinos. Estaban agrupados en cuatro tribus diferentes: los Selk'nam, los Haush, los Yámanas y los Alakaluf.

La llegada de los europeos cambió radicalmente la vida en Karukinka. El interés de los recién llegados por navegar y cartografiar el área se explica por la importancia estratégica que tenía en ese momento el Estrecho de Magallanes y la ruta de Cabo de Hornos para la navegación mundial, hasta la apertura del canal de Panamá en 1914.

\subsection{Distribución de los haruwen ${ }^{6}$}

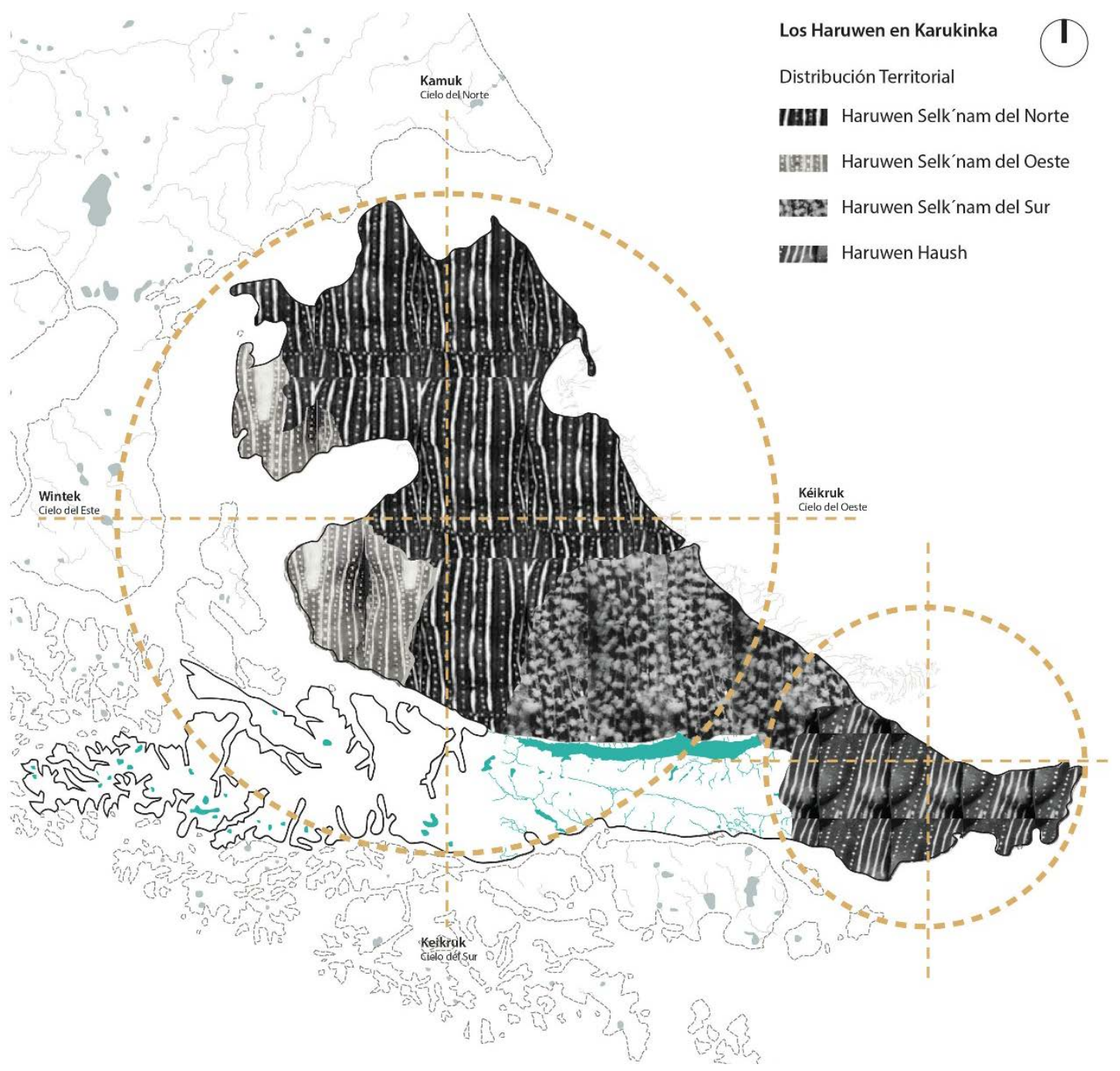

Fig. 07. Plano de la distribución territorial de los haruwen, según los cuatros cielos Selk'nam en Karukinka. Cada haruwen fue representado por los patrones de las pinturas tradicionales de los pechos Selk'nam. Fuente: Elaboración propia, a partir de reinterpretación del plano y registro de M. Gusinde (1980), C. Keller (1947) y N. Reyes (2012).

${ }^{6}$ Haruwen: significa "Tierra" para los Selk'nam. Cada haruwen correspondía a uno de los cuatro puntos cardinales (norte, sur, este y oeste) y representaba una porción espacial de tierra en Karukinka. El haruwen con mayor poder era el del Este (Keller, 1947). 
La repartición y división del territorio Selk’nam en la isla de Karukinka, está basada en la concepción de su nomadismo y la creencia en los cuatro cielos (Gusinde, 1980). Eran un pueblo de cazadores que vivían en grupos de familia de unos treinta o más individuos dentro de los límites de un territorio determinado para evitar conflictos con grupos étnicos vecinos (Prieto, 1984). La organización territorial se basaba en un círculo dividido en cuadrantes, los sho'on ${ }^{7}$. El significado del círculo representaba el universo. De cada uno de los sho'on eran una fuente de poder y energía y el más importante era el sho'on del Este. Como puede observarse en la Fig. 07, cada haruwen pertenecía a uno de los cuatro sho'on y se representaba espacialmente en la isla (Keller, 1947). Según Martin Gusinde (1980) existían solo 39 haruwen sin embargo Anne Chapman (1986 y 1989) asegura que había 82. Cada haruwen estaba asociado a un punto cardinal y la persona nacida en el mismo debía cumplir ciertas tradiciones.

\subsection{Del haruwen a la piel y viceversa}
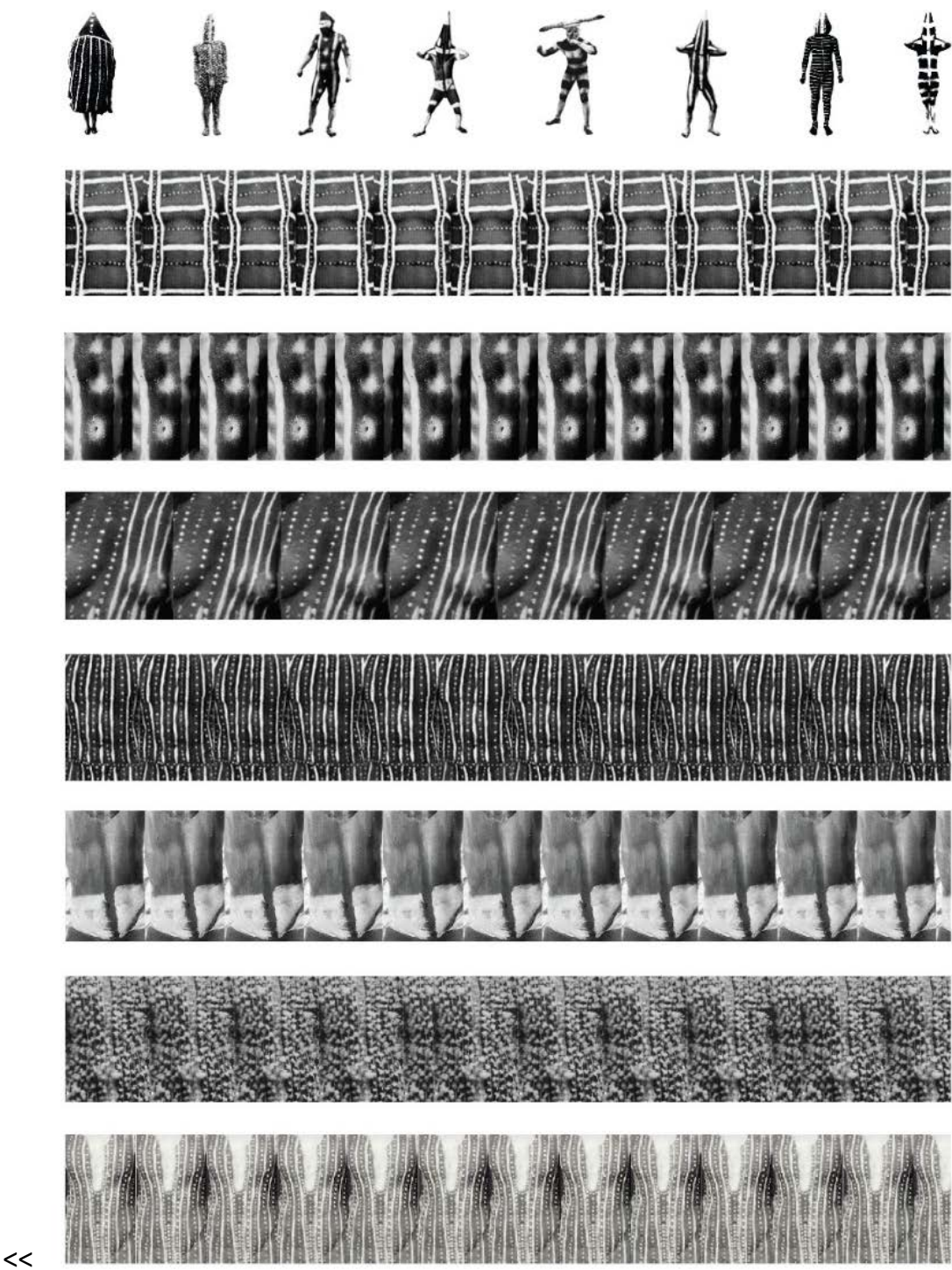

Fig. 08. Patrones de pintura sobre pecho Selk'nam. Ceremonia Hain o Kloketen. Rito de iniciación. Pintura a base de pigmentos del territorio. Fuente: Elaboración propia, a partir del recorte y repetición en photoshop de fotografías de los pechos de los hombres Selk'nam tomadas por Anne Chapman (2002).

7 Sho'on: significa "Cielo y/o puntos cardinales" para los Selk'nam. 
La importancia del haruwen para los pueblos originarios no solo era representada por la forma de habitar el territorio, sino que también lo plasmaban en su cuerpo (ver Fig. 08). Literalmente, pintaban sus pechos para ceremonias importantes. El ritual de los pechos pintados se realizaba a los trece años para el miembro de la tribu. Personificaba el verdadero arte en ellos, representando simbólicamente sus creencias y mitos. Siendo el pecho lo más vital del ser humano, vinculado al corazón y a las emociones, allí es donde llevan grabada la tierra, sus vivencias y sus afectos.

\section{LA FORMA ANTROPICA SEDENTARIA DE KARUKINKA}

\subsection{Llegada del hombre europeo}

"...un país montañoso, con vastas bahías y numerosos canales, que se hunden en la tierra, en este clima que reviste matices que parecen conducir fuera de los límites de este mundo..." Charles Darwin, 1830.

Tal como lo relata Garcés (2009), desde Pigafetta a Darwin, desde Sarmiento de Gamboa a Gusinde, Karukinka ha sido explorada a partir del primer avistamiento por $\mathrm{H}$. de Magallanes, quien en 1520 dio con el estrecho que lleva su nombre. En 1584, P. Sarmiento de Gamboa impulsó la fundación de asentamientos humanos en la isla pero fracasó por las dificultades en la falta de provisiones para sus habitantes. Desde entonces se sucedieron numerosas expediciones, entre ellas la de Ch. Darwin entre 1830 y 1834. Luego en 1886 arribó J. Popper (2010), quien fue el primero en recorrer el interior de la isla descubriendo un yacimiento aurífero y en cuya cercanía propuso la fundación de un pueblo marítimo llamado Atlanta. Fue un adelantado en la campaña de exterminio de los aborígenes. Otro europeo M. Braun, radicado en Puerto Arenas - Chile, fue el encargado de organizar y administrar desde 1893 la Sociedad Explotadora de Tierra del Fuego, formada a partir de una concesión de tierras ${ }^{8}$ que superó el millón de hectáreas. La colonización económica desarrolló un conjunto de asentamientos humanos llamados los company lands ${ }^{9}$, que transformaron radicalmente el territorio de Karukinka en un sistema de infraestructura y estancias para la explotación de los recursos naturales de la isla. Los usos eran agrarios y mineros, con la idea de una región activada en términos empresariales mediante instalaciones industriales, asentamientos humanos, infraestructura vial y portuaria. Los agrarios en forma de grandes sociedades que administraban las estancias ganaderas. Y mineros representados por la Empresa Nacional del Petróleo (ENAP).

\subsection{Demografía, límites y distribución territorial}

A partir de 1862 con el gobierno de B. Mitre, la Argentina logro dejar atrás las guerras internas y dio comienzo a un sostenido crecimiento económico y demográfico que se manifestó en la ocupación de la pampa y la preocupación por poblar todos los territorios que le pertenecían, principalmente los de la Patagonia. Sin embargo, para sus intereses estratégicos y económicos, el Estrecho de Magallanes, la Isla Grande de Tierra del Fuego y sus cercanías poseían un valor muy inferior al vital que le confería Chile. Ya que geográficamente Chile necesitaba acortar sus distancias para comercializar con Europa y en aquella época el canal de Panamá aún no estaba abierto, por lo que la ruta marítima de Cabo de Hornos era muy importante y estratégica.

\footnotetext{
${ }^{8}$ Concesión de Tierras chilenas: sistema adoptado por algunos gobiernos chilenos, como forma de entregar a empresas y sociedades ganaderas el arriendo las tierras fueguinas por plazos de hasta 25 años.

${ }^{9}$ Company lands: apoyo, complemento y extensión de las company town. Conjunto de instalaciones unidas a un lugar de extracción minera, de ubicación remota y alejada de los núcleos de población. Cuya propiedad pertenece a los propietarios de la empresa.
} 
En cuanto a la preocupación por poblar los llamados "territorios nacionales argentinos", en 1869 a fines de la guerra del Paraguay y antes de la Conquista de Chaco $^{10}$ y del Desierto ${ }^{11}$, se hizo el primer censo nacional de personas. Descubriendo que sobre una extensión de $2.797 .113 \mathrm{~km}^{2}$ se mal distribuían 1.877 .490 habitantes, ubicándose sólo el $34 \%$ de ellos en los centros urbanos. Veintiséis años después, en 1895, se realizó el segundo censo nacional y el recuento era de 4.094 .011 habitantes, de los cuales el 42,8\% se aglomeraba en las zonas urbanas (INDEC, 2003). El panorama en la porción Argentina de Isla Grande de Tierra del Fuego denominada Tierra del Fuego, de 21.499 km², se manifestó mucho más despoblado, con una densidad de 0,02 hab/ha. La cifra dio un total de 477 habitantes, 288 en Ushuaia, 73 en San Sebastián, 53 en la Isla de los Estados, 24 en la Estancia Haberton y la mitad eran extranjeros (Blasi, 1978).

Tal como relata Belza (1975), la conocida frase de J. B. Alberdi "gobernar es poblar" fue utilizada como dogma político nacional e hizo que se abrieran las puertas de la Argentina a la inmigración europea. El presidente Avellaneda ensayaba un nuevo fomento de la colonización, que consistía en atraer al inmigrante por medio de una legislación agraria del año 1876. De este instrumento legal nació en 1880 la Oficina de Tierras y Colonias; se organizó la exploración del Chaco, La Pampa, Misiones y la Patagonia; se delinearon y mensuraron pueblos y colonias; se otorgaron derechos de arrendamiento y propiedad y se remataron terrenos del Estado. La autorización del art. № 104 permitía “... al Poder Ejecutivo conceder tierras a empresas particulares para poblar en los Territorios Nacionales que no estuvieran medidos y dados a la colonización...". Esto desató el fenómeno de la especulación sobre la tierra fiscal ${ }^{12}$.

En 1889 se llevó a cabo el "abrazo del estrecho" donde se juntaron los presidentes Federico Errázuriz Echaurren de Chile y Julio A. Roca. Donde este último instó a los estancieros Menéndez y Braun entre otros, a explotar la despoblada Patagonia Argentina. Víctimas de este proceso de ocupación del territorio, los Selk'nam fueron cruelmente perseguidos en cacerías organizadas por empresarios del oro. En cautiverio muchos murieron por enfermedad o desadaptación.

\section{"... de un punto denominado Espíritu Santo..."}

La Isla Grande de Tierra del fuego es territorio chileno y argentino y el límite entre ambos países no se debe a un accidente geográfico sino a un Tratado y a una línea imaginaria: un Meridiano (ver Fig. 09). “...Así fue como el 13 de marzo se colocó el primer mojón, una estaca de roble, cerca de Cabo Espíritu Santo. Tomó las visuales de Punta Catalina y de Cabo Vírgenes y situó la línea divisoria entre Argentina y Chile, de acuerdo al artículo 3o del tratado de 1881 que establecía como límite el meridiano 68 34’ a partir del punto cabo Santo Espíritu..." Belza (1975).

\footnotetext{
${ }^{10}$ Conquista de Chaco: (1870-1917) avanzada y ocupación militar de la frontera norte del país, en poder de los pueblos originarios.

${ }^{11}$ Conquista del Desierto: (1878 -1885) sangrienta campaña militar Argentina por la que se conquistó grandes extensiones de territorio pampeano y patagónico en poder de los pueblos originarios, quienes fueron sometidos, perdiendo su identidad y/o asesinados.

12 Tierra fiscal: término utilizado en la Argentina para denominar a los lotes, terreno o Parcelas de tierra, que forman parte del territorio de un Estado.
} 


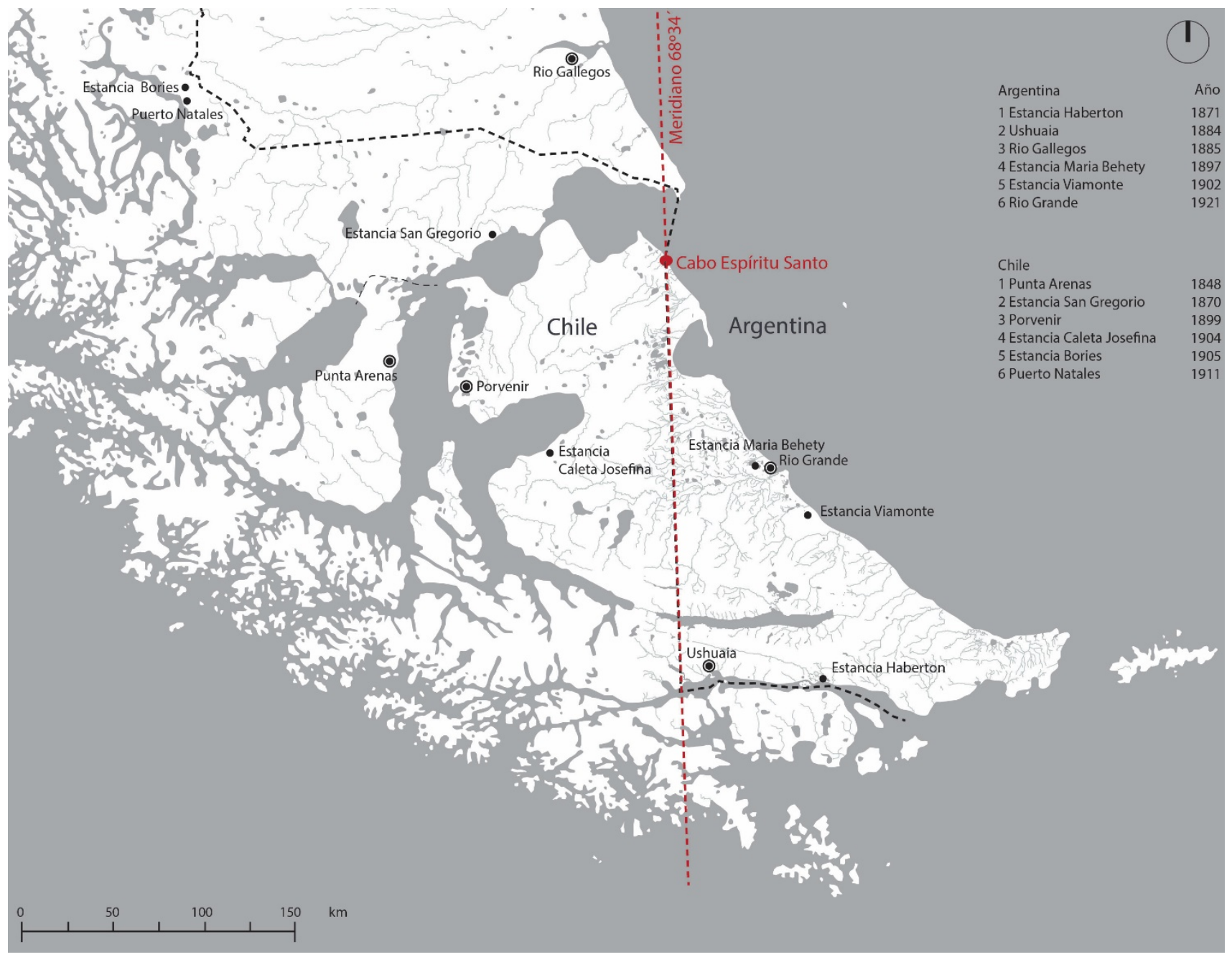

Fig. 09. Plano límites territoriales contemporáneos, ciudades, estancias y año de fundación en Isla Grande de Tierra del Fuego. Fuente: Elaboración propia, a partir de libro En la isla del Fuego, 2o colonización. Juan E. Belza. (1975).

En el año 1891, el Departamento de Obras Publicas de la Nación realiza un informe y el agrimensor Julio V. Díaz se encarga de hacer el Plano de Mensura del sector Argentino de Tierra del Fuego. De dicho plano (ver Fig. 10) se observa que intentan tomar como bordes los accidentes geográficos como los ríos y el mar Argentino. Al Este por el Tratado del Meridiano 680 34' y luego delimita las parcelas con trazas ortogonales orientadas según los puntos cardinales Norte-Sur y Este-Oeste. 

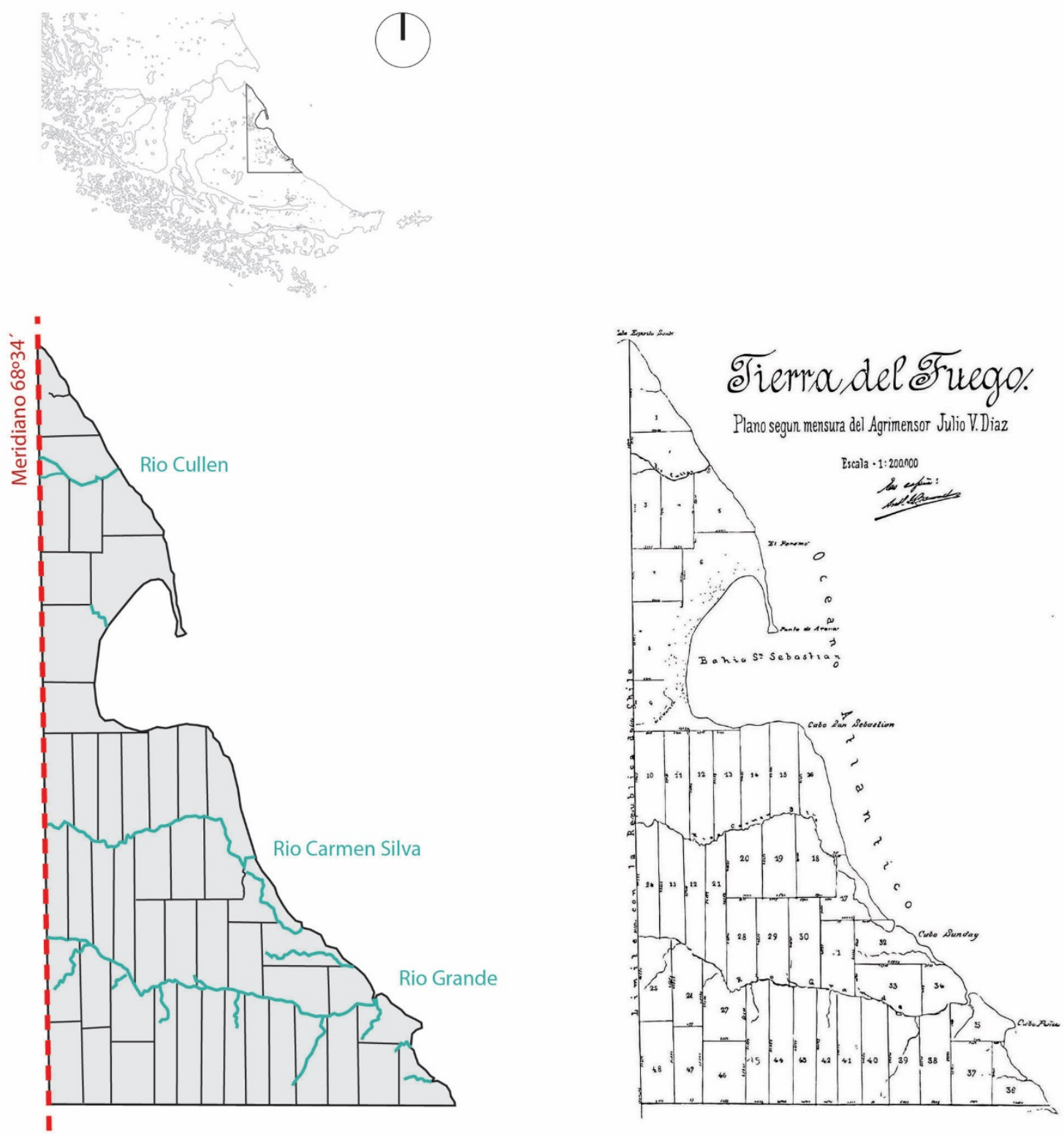

Fig. 10. Cartografía de 1891, según mensura del agrimensor Díaz. Esquema del parcelamiento del territorio. Fuente: Elaboración propia, a partir de la cartografía de Díaz (Belza, 1975).

\subsection{De la práctica a la Ordenanza urbana. Un modelo constante y uniforme.}

Todo el proceso de colonización española en América sucedió en la ocupación del territorio y es por ello que las ciudades jugaban un papel estratégico fundamental, como núcleo estable para la defensa, la administración, la extensión de la cultura, la explotación de los recursos y la continuidad de la penetración. Y así fue como cientos de miles de fundaciones fueron creadas desde California hasta la Patagonia.

Según F. de Terán (1997), a través de los planos fundacionales, puede verse la consolidación y extensión del "modelo de ciudad", su desarrollo, uso y materialización. Sin embargo, no se trata de un patrón explicito previo al comienzo de las fundaciones, sino de un conjunto de coincidencias que se dan de forma reiterada y que posibilita pensar en la existencia 
de características previas, asumidas implícitamente y que, gracias a la rica experiencia fundacional de ensayo a prueba y error, se construyó un patrón a posteriori. Cabe aclarar que existía un "Modelo oficial" de la Corona española pero no es tomado en cuenta. El primer texto real de normativa urbanizadora oficial fue la Ordenanza de Carlos I en 1523, en la que habla de la adopción de la cuadricula como trazado de las fundaciones españolas en América. Desde este texto hasta las Ordenanzas de Felipe II en 1573, hay pocas indicaciones más de la Corona sobre la forma de la ciudad. Aclarando también que el texto de 1573 apareció cuando la mayor parte de las principales ciudades estaban ya fundadas y la cuadricula se había impuesto como modelo principal para el trazado fundacional. Entonces, las Ordenanzas de Felipe II fueron un importante código político-urbanístico que, en sus disposiciones formales, recogen por una parte el resultado de una experiencia ya realizada en la práctica, sin normativa oficial. Es decir, la práctica precedió a la norma, constituyendo a ésta a posteriori.

El "modelo de ciudad" se trataba de ciudades de trazado geométrico en el que las calles rectas se cortan formando manzanas trapezoidales, rectangulares o cuadradas, este último llamado “Cuadricula española” (Terán 1997). Cuando una de las manzanas centrales queda libre de edificación convertida en Plaza Mayor, se llama "Modelo clásico de ciudad hispanoamericana" (López de Velasco, 1971). Algunos elementos más, cuya reiteración sistemática permitió realizar el modelo a posteriori, son el sistema de división parcelaria y la forma que adopta la edificación, la distribución de los usos y la definición de los espacios públicos y privados. Pero lo ideal es concluir que "no hubo una sola fuente de origen y que lo más probable es que resultaron de una miscelánea de prácticas, experiencias y teorías europeas, junto con prácticas indígenas" (Wilgus 1969).

\subsection{El ejemplo de la ciudad de Ushuaia. Desarrollo moderno del modelo clásico de cuadricula española.}

Un ejemplo significativo en la Isla Grande de Tierra del Fuego es la ciudad de Ushuaia, actual capital de la provincia de Tierra del Fuego, Antártida e Islas del Atlántico Sur de Argentina. Fue fundada en 1884 por Lasserre en el Fuerte Ushuaia sobre el solar del Convento de San Uriel Arcángel de los Vientos Australes. La ciudad de apariencia ejidal tipo costa (ver Fig. 11), se emplaza en la bahía de Ushuaia, sobre el Canal de Beagle y está rodeada por la cadena montañosa del Martial. No hubo delineación de calles ni manzanas hasta 1894. Y en 1896 se creó la Colonización Penal, una cárcel extrema seguridad donde eran enviados los hombres de todo el país a cumplir sus penas.

El desarrollo urbano de Ushuaia fue más por objetivos políticos de efectivización geopolítica que un armónico programa urbanístico (ver Fig. 12). Los tiempos apremiaban y era necesario poblar rápidamente las zonas alejadas e inhóspitas del país. Las construcciones de la primera década de la ciudad entre 1884 y 1894, se basaron en la necesidad de alojar a una heterogénea población, en su mayoría inmigrantes, originando un conjunto de viviendas sin las condiciones elementales para vivir en un clima tan extremo.

La cuadricula urbana se inserta sobre una topografía difícil debido a la pronunciada pendiente hacia la costa marítima del Canal de Beagle. El casco histórico está conformado por un damero de 14 manzanas de largo por tres de ancho. Se observa la ausencia de una Plaza Mayor, aunque si dos plazas secundarias (ver Fig. 13). Por fuera de la ciudad el territorio era tierra fiscal, con estancias como apoyo para el uso y explotación agrícola y minero.

Varios relatos de exploradores descritos por Lupiano (1997), detallan minuciosamente a la ciudad, como por ejemplo Otto Nordenskjord en 1896 quien afirmaba que “... la capital del extremo sur es un conjunto irregular de barracas. La casa más hermosa es la casa de gobierno, las demás son bajas, de madera, recubiertas por chapas de zinc y precedidas por un jardincito...".En este contexto los edificios antiguos eran destinados a uso residencial o mixto (residencial y comercial) conformando un mosaico dentro de la grilla de la ciudad. 

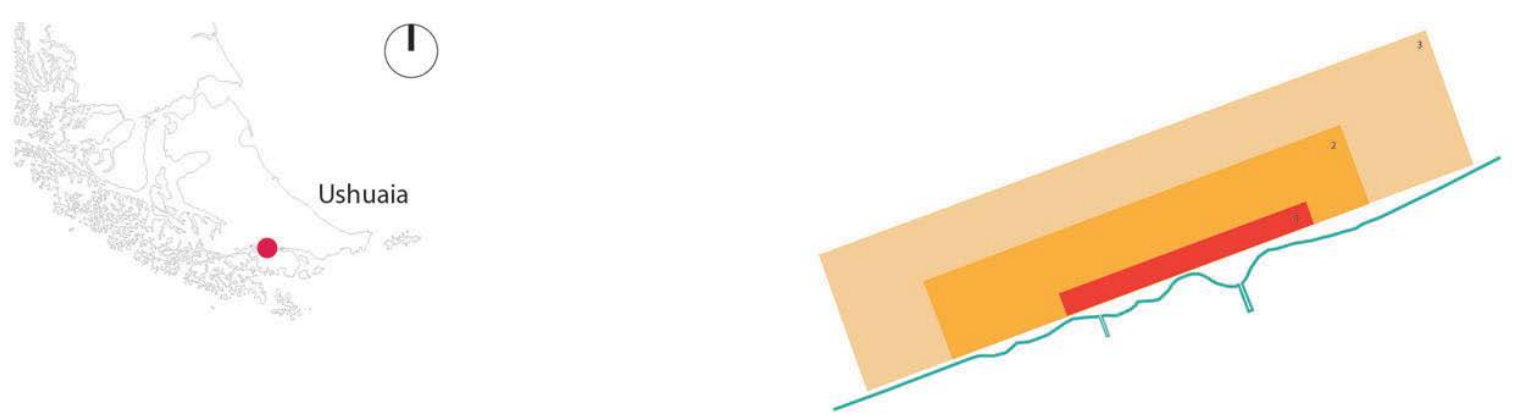

Fig. 11. Esquema de configuración ejidal ${ }^{13}$, ciudad de Ushuaia 1903. Ejemplo de ejido tipo costa. Fuente: Elaboración propia, a partir de esquemas similares de tesis doctoral M. Pesoa Marcilla (2016).

| 1894

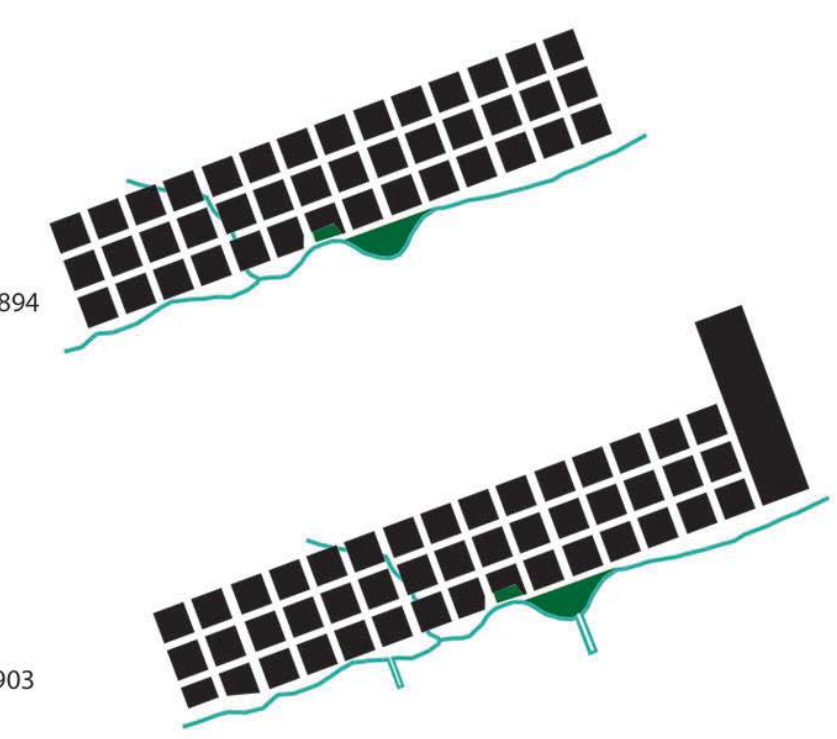

Cuadrícula regular
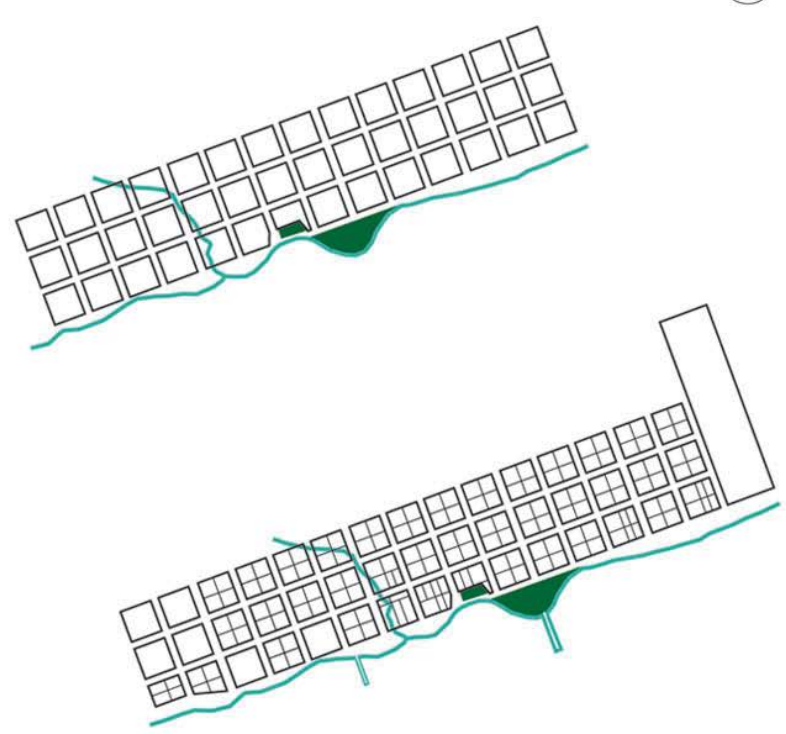

Parcelación manzanas

Fig. 12. Esquemas de crecimiento de la ciudad de Ushuaia en 1894 y 1903. La cuadricula regular y la parcelación de las manzanas. Fuente: Elaboración propia, a partir de planos extraídos de P. Vairo (1996).

13 Ejido: (exītus = salida) Son las "tierras de uso común no cultivables a la salida de los poblados, del lati exitus que significa salida" Joaquín Escriche (citado por Barcos, 2012). En la práctica de las fundaciones hispano-americanas era el campo común de un pueblo, lindante con él, que no se labra, y donde suelen reunirse los ganados o establecerse las eras. En la práctica argentina, desde el siglo XVI-II es la tierra de cultivo alrededor de las ciudades, llamada "de pan llevar", que se consolida en la legislación a partir de la década de 1820 (Pesoa Marcilla, 2016). 


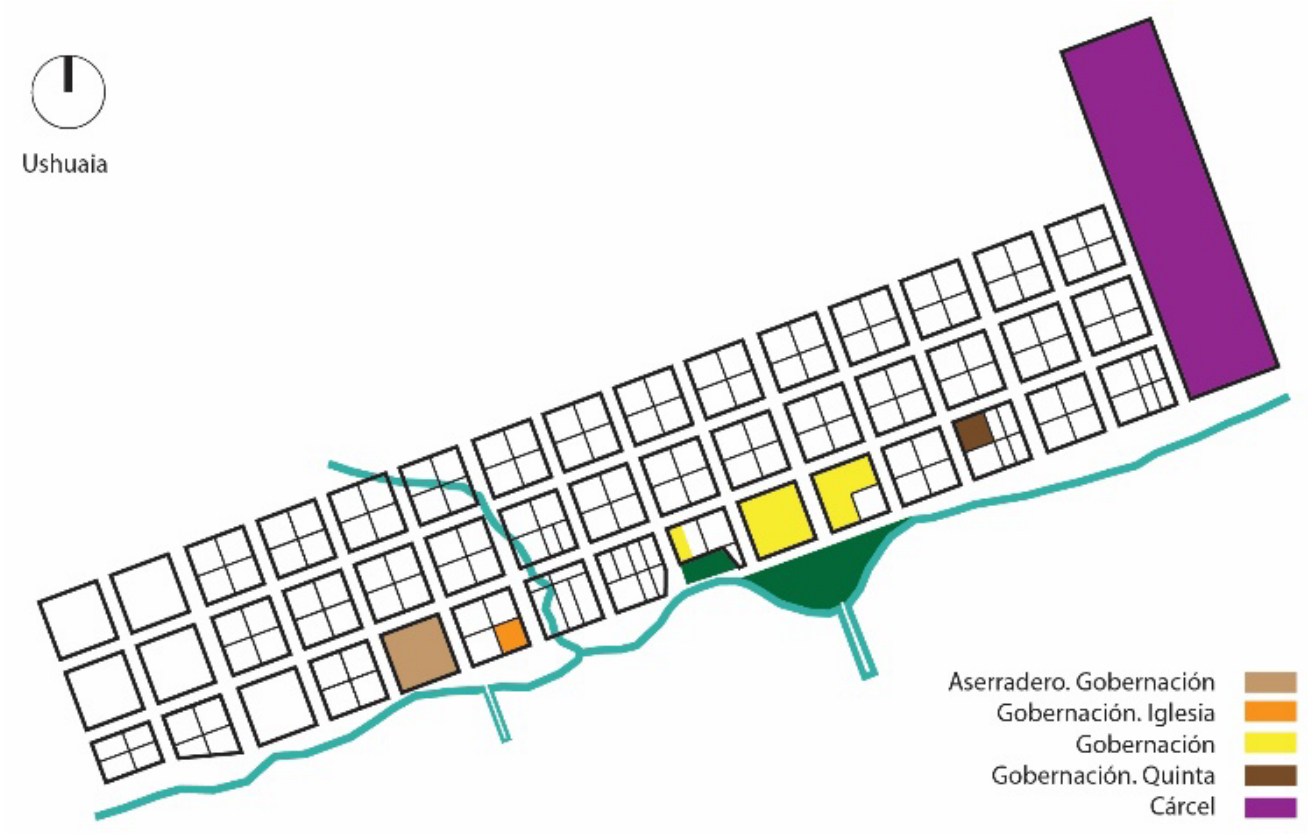

Fig. 13. Usos en la ciudad de Ushuaia, 1903. Fuente: Elaboración propia, a partir de planos extraídos de P. Vairo (1996).

\section{REFLEXIONES FINALES}

Tras las huellas de la forma urbana en la isla de Karukinka o Isla Grande de Tierra del Fuego, se observa ya desde los primeros pobladores los Selk'nam la idea del vínculo con el orden universal. Es decir, según los ejes astronómicos, los Selk'nam ubicaban bajo las estrellas los puntos cardinales para luego trasladarlos al suelo, dándole así la forma a su territorio. Tal cual como en las ciudades griegas, las romanas y luego en las de la América española.

Luego con la colonización, el "modelo clásico español" fue el utilizado como principio de la forma urbana. En el caso de la ciudad de Ushuaia, se observan similitudes y diferencias con respecto al modelo. La ciudad está rodeada de un anillo exterior de ejido, de carácter de tierra fiscal, pero la explotación de dicha tierra para uso agrícola estaba a cargo de los estancieros a quienes el Estado les otorgaba una concesión de 25 años aproximadamente. Luego comienza la retículacuadrícula urbana, símbolo de conquista y civilización ante la barbarie a pesar de la accidentada de la topografía de Ushuaia. La parcelación es heterogénea, aunque la mayoría divide la manzana en cuartos, que a su vez subdivide cada vez más al acercarse al centro de la ciudad. La manzana es de forma regular, cuadrada. Según Vairo (1996) no estuvo proyectada una Plaza Mayor, como en el "modelo clásico de ciudad hispanoamericana", sin embargo, en la cartografía de la época se observan dos plazas secundarias como espacios cívicos y públicos, la principal por sus dimensiones y su emplazamiento sobre el Canal de Beagle y la secundaria, más pequeña dentro de una manzana compartida por el edificio de la Gobernación. El equipamiento de la ciudad está dado por la Gobernación, la Iglesia, el Aserradero, la Quinta y una Cárcel de escala nacional y las demás parcelas están destinadas a uso de viviendas y comercios.

De estas reflexiones y a modo de síntesis, las huellas de la forma urbana en el territorio de Karukinka se ven reflejadas por el modelo clásico español, impulsado desde la conquista de América a prueba de ensayo y error. Pero debido a la ubicación austral de esta isla, su colonización ha llegado más tarde y por lo tanto con la Ordenanza de Felipe ll en vigencia. A pesar de ello lo importante es la experiencia de las anteriores ciudades fundadas en América, como modelo de ciudad para la forma urbana austral. 


\section{BIBLIOGRAFÍA}

BARCOS, M. F. (2012) El influjo del Derecho Indiano en la legislación sobre ejidos de la Provincia de Buenos Aires, $1782-$ 1870. Revista de Indias, vol. LXXII, 256, p. 687-716.

BELZA, J. (1975) En la isla del fuego, 10 Encuentros. Buenos Aires, Argentina. Instituto de investigaciones históricas de Tierra del Fuego.

BELZA, J. (1975) En la isla del fuego, 2o Colonización. Buenos Aires, Argentina. Instituto de investigaciones históricas de Tierra del Fuego.

BELZA, J. (1975) En la isla del fuego, 3o Población. Buenos Aires, Argentina. Instituto de investigaciones históricas de Tierra del Fuego.

BLASI, H. (1978) Evolución de la población patagónica entre los censos de 1895 y 1914 . Trabajos y Comunicaciones, no 23, p. 29-40. En Memoria Académica. [Consulta: Enero, 2019] Disponible en http://www.memoria.fahce.unlp.edu.ar/art revistas/pr.1103/pr.1103.pdf

CHAPMAN, A. (1986) Los Selk'nam. La vida de los Onas. Emecé Editores, Buenos Aires, Argentina.

CHAPMAN, A. (1989) El fin de un mundo. Los Selk'nam de Tierra del Fuego. Buenos Aires, Argentina. Vázquez Mazzini Editores.

CHAPMAN, A. (2002) Fin de un Mundo. Los Selkmam de Tierra del Fuego. Culturas tradicionales. Patagonia. Editorial Taller Experimental Cuerpos Pintados, Santiago de Chile.

CORBOZ, A. (1983) Le territoire comme palimpseste. Revista Diogène, no 121, p. 14-35.

DARWIN, CH. (1996) Darwin en Chile. Editorial Universitaria, Santiago de Chile.

GAJARDO, R. (1993) La vegetación natural de Chile: clasificación y distribución geográfica. Editorial Universitaria, Santiago de Chile.

GARCÉS, E. (2009). Identidad e Imagen Paisajes culturales extremos en Tierra del Fuego. Revista Diseña, no 1, p. $24-35$. [Consulta: Enero, 2019] Disponible en http://www.revistadisena.com/identidad-e-imagen-paisajes-culturales-extremosen-tierra-del-fuego/

GONZALEZ MARMOL, J. M. (2012) Carta celeste del mes de febrero en el hemisferio Sur. [Consulta: Enero, 2019] Disponible en http://www.astroyciencia.com/archivos/Cartas-Celestes-Febrero.pdfGUSINDE, M. (1980) Expedición a Tierra del Fuego. Editorial Universitaria, Santiago de Chile.

INDEC. Instituto Nacional de Estadística y Censo (2003) Historia demográfica Argentina, 1869-1914. Dirección de Difusión, Buenos Aires. [Consulta: Enero, 2019] Disponible en https://www.indec.gob.ar/bicentenario/pdf/Introduccion.pdf

INDEC. Instituto Nacional de Estadística y Censo (2010) Datos poblacionales provincia de Tierra del Fuego, Argentina. [Consulta: Enero, 2019] Disponible en https://www.indec.gob.ar/ftp/censos/2010/CuadrosDefinitivos/P1P_Tierra_del_fuego.pdf

INE. Instituto Nacional de Estadística (2002) Datos poblacionales provincia de Magallanes, Chile. [Consulta: Enero, 2019] Disponible en https://redatam-ine.ine.cl/redbin/RpWebEngine.exe/Portal?BASE=CENSO_2002\&lang=esp

IGM. Instituto Geográfico Militar, Chile. [Consulta: Enero, 2019] Disponible en https://www.igm.cl/\#* 
IGN. Instituto Geográfico Nacional, Argentina. [Consulta: Enero, 2019] Disponible en http://www.ign.gob.ar/

Instituto de Geología y Recursos Mineros. SEGEMAR, Argentina. [Consulta: Enero, 2019] Disponible en http://sig.segemar.gov.ar/

KELLER, C. (1947) Dios en Tierra del Fuego: Mitos y cuentos de los Selk'nam. Editorial Zig-Zag, Santiago de Chile.

LOPEZ DE VELASCO, J. (1971) Geografía y Descripción Universal de las Indias. Editorial BAE, Madrid, España.

LUPIANO, L. (1997) Ushuaia: algunos aspectos del patrimonio arquitectónico urbano. Editorial Dunken, Buenos Aires.

MUMFORD, L. (1957) La cultura de las ciudades. Editorial Emecé, Buenos Aires, Argentina.

National Aeronautics and Space Administration. NASA. Landsat Science, Copernicas. [Consulta: Enero 2018]. Disponible en https://landsat.gsfc.nasa.gov/category/news/data/

National Aeronautics and Space Administration. NASA. Misión Topografía del Radar de Shuttle (SRTM). [Consulta: Enero 2019]. Disponible en https://www2.jpl.nasa.gov/srtm/

PESOA MARCILLA, M. (2016) Una ciudad para la pampa. La construcción del territorio en la Provincia de Buenos Aires (1810-1916). Tesis doctoral Urbanismo. Universidad Politécnica de Catalunya, Barcelona.

PONCE, J. F. y RABASSA, J. O. (2012) Geomorfología glaciar de la Isla de los Estados, Tierra del Fuego, Argentina. Editorial Sociedad Geológica de España. Revista de la Sociedad Geológica de España, vol. 25, p. 67-67. [Consulta: Enero, 2019] Disponible en http://www.sociedadgeologica.es/archivos/REV/25(1-2)/art06.pdf

POPPER, J. (2010) Atlanta. Proyecto para la fundación de un pueblo marítimo en Tierra del Fuego y otros escritos. Editorial Eudeba, Buenos Aires, Argentina.

PRIETO, A. (1984) Los Selk'nam: Una sociedad satisfecha. Revista Ans Inst. Pat. Cs. Ss., vol. 15. Punta Arenas, Chile.

RABASSA, J. O. (2008) Late Cenozoic glaciations in Patagonia and Tierra del Fuego. The Late Cenozoic in Patagonia and Tierra del Fuego, Elsevier. Revista Developments in Quaternary Sciences, vol. 11, p. 151-204. Amsterdam. [Consulta: Enero, 2019] Disponible en http://patagonia.byu.edu/portals/65/docs/rabassadqs.pdf

REYES, N. (2012) Territorio y Espacio Selk'nam. [Consulta: Enero 2018]. Disponible en https://es.slideshare.net/nicolasrevesvilches/territorio-selknam-14131138

SABATE BEL, J. (1999) El proyecto de la calle sin nombre: Los reglamentos urbanos de la edificación. Editorial Fundación Caja Arquitectos, Barcelona.

SOLA-MORALES, M. (1999) Prólogo del libro El proyecto de la calle sin nombre: Los reglamentos urbanos de la edificación. Sabaté Bel, J. Editorial Fundación Caja Arquitectos, Barcelona.

SOLA-MORALES, M. (1981) La identidad del territorio. Reconocimiento comarcal y ordenación del territorio. Revista Cuadernas arquitectura i Urbanismo, extra no 1 FONT, A. (2007) La explosión de la ciudad. Transformaciones territoriales en las regiones urbanas de la Europa Meridional. Ediciones Ministerio de Vivienda, Barcelona.

TERAN DE, F. (1997) La ciudad hispanoamericana: El sueño de un Orden. Editorial Centro de Estudios Históricos de Obras Públicas y Urbanismo, Madrid, España.

VAIRO, P. (1996) Ushuaia, su historia. Editorial Zaguera \& Urutí, Buenos Aires, Argentina. 
WILGUS, A. (1969) Historical Atlas of Latin América: political, geographic, economic, cultural. Nueva York, Estados Unidos. 


\section{ANEXO}

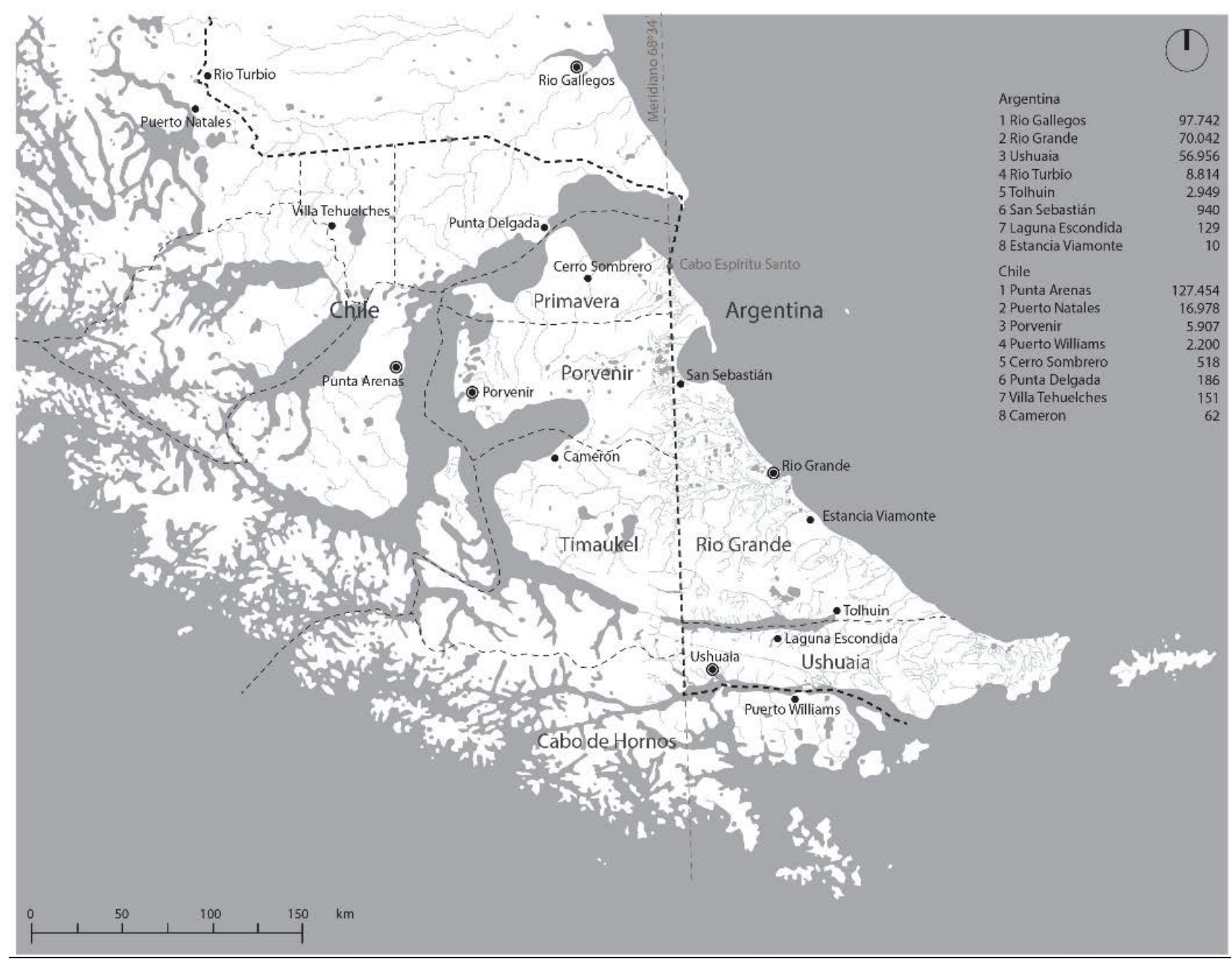

Fig. 14. Plano límites territoriales contemporáneos, ciudades y cantidad de habitantes en Isla Grande de Tierra del Fuego 2015. Fuente: Elaboración propia, a partir de libro En la isla del Fuego, 2o colonización. Juan E. Belza. (1975) y los datos poblacionales: Instituto Nacional de Estadística y Censos de la República Argentina (INDEC, 2010) e Instituto Nacional de Estadísticas Chile (INE, 2002). 

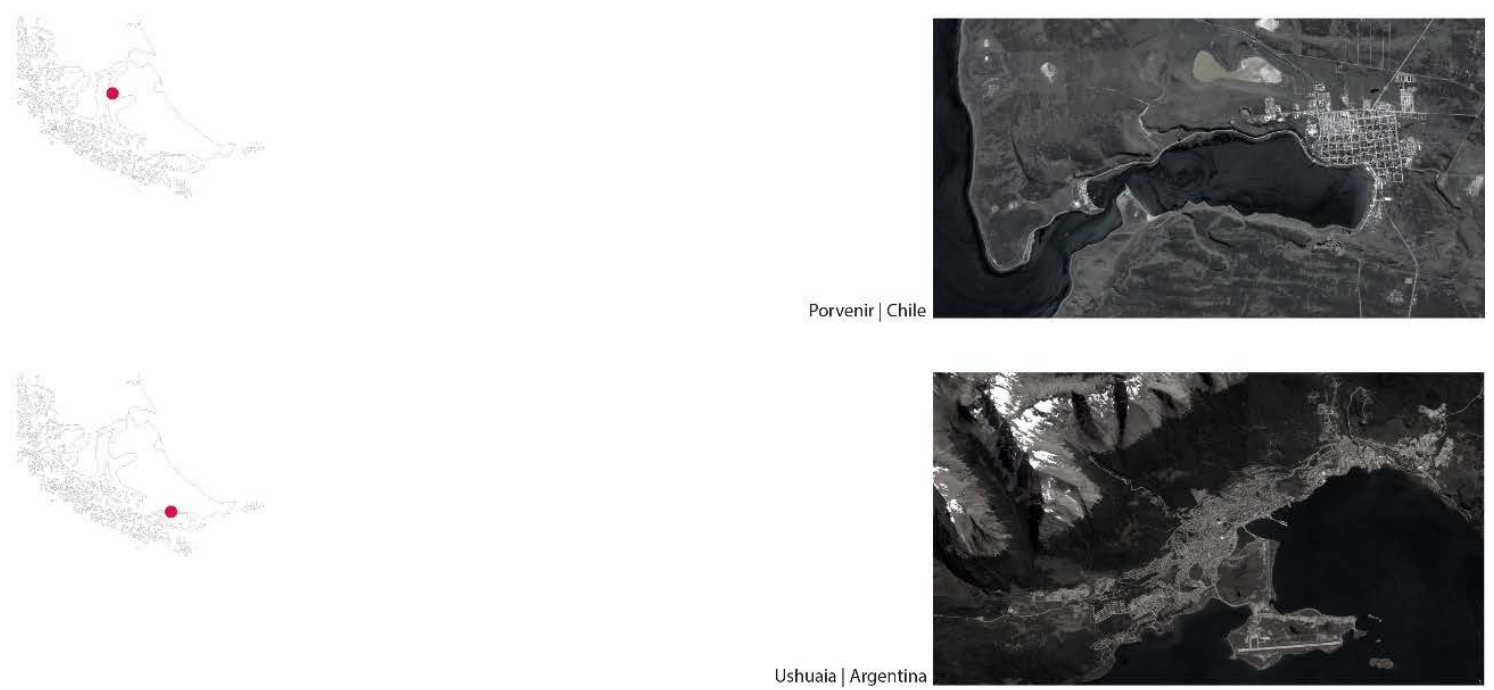

Ushuaia | Argentin

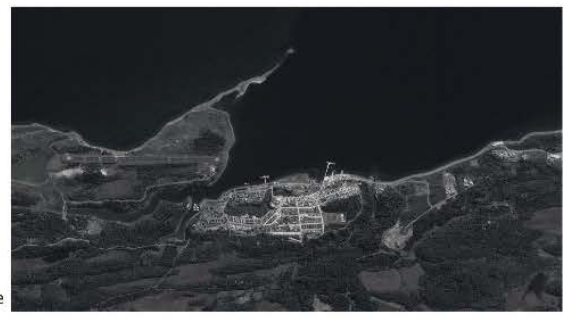

Puerto Williams $\mid$ Chile

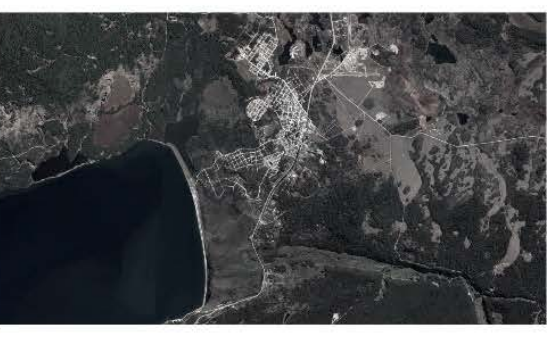

Tolhuin | Argentin

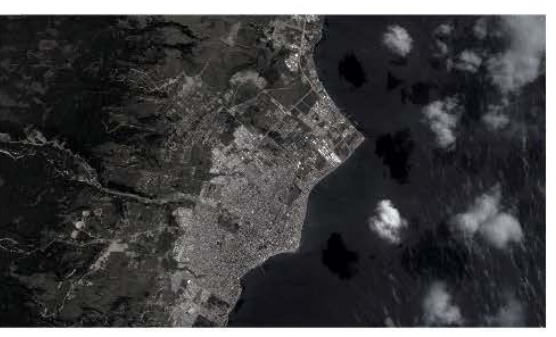

Puerto Arenas | Chi

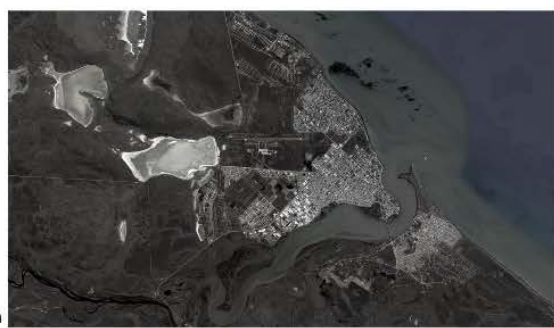

Fig. 15. Imágenes aéreas de las ciudades actuales de Isla Grande de Tierra del Fuego. Fuente: retoques en fotografías, a partir del Google Earth Pro 2018. 